\title{
Desain High Temperature Gas-Cooled Reactor (HTGR) Model Geometri Heksagonal Dua Dimensi dengan Bahan Bakar Thorium Hasil Daur Ulang
}

\author{
Mutia Utari*, Yanti Yulianti, dan Agus Riyanto
}

Jurusan Fisika, Universitas Lampung, Bandar Lampung, Indonesia, 35141

\begin{tabular}{|c|c|}
\hline Article Information & Abstract \\
\hline $\begin{array}{l}\text { Article history: } \\
\text { Received } 10 \text { Maret } 2020 \\
\text { Received in revised form } \\
\text { 10Maret } 2020 \\
\text { Accepted } 30 \text { Maret } 2020\end{array}$ & $\begin{array}{l}\text { The Research about the design of high temperature helium gas-cooled reactor } \\
\text { (HTGR) terraces with thorium fuel recycled using the SRAC program has been } \\
\text { completed. This research includes the percentage of fuel enrichment, reactor core } \\
\text { size, reactor core configuration, criticality, and the distribution of the power density. } \\
\text { The calculation of reactor core is done in two dimensions } \backslash s f r a c\{1\}\{6\} \text { hexagonal } \\
\text { terrace section with a triangular mesh. The fuel is used, i.e. thorium with a burn-up } \\
\text { of } 20 \mathrm{GWd} / \mathrm{t} \text { and } 30 \mathrm{GWd} / \mathrm{t} \text {, and helium gas as a cooler. The results obtained in } \\
\text { this study show that the ideal HTGR reactor core design with reactor core size and } \\
\text { configuration are }(x) 22 \mathrm{~cm} \text { at point }(y)=2035,05 \mathrm{~cm} \text { and at }(y) 11 \mathrm{~cm} \text { at point }(x)= \\
2035,05 \mathrm{~cm} \text {, then enrichment in fuel } 8 \% \text {. The result of maximum power density is } \\
550.3685 \mathrm{Watt} /\{\mathrm{cm}\}\}^{\wedge} 3 \text { where the position at }(x)=22 \mathrm{~cm} \text { and axis }(y)=11 \text { with the } \\
\text { effective multiplication factor value }\{(k\}-\{e f f\}) \text { of } 1,0000002\end{array}$ \\
\hline
\end{tabular}

Informasi Artikel

Proses artikel:

Diterima 10 Maret 2020

Diterima dan direvisi dari

10 Maret 2020

Accepted 30 Maret 2020

\section{Kata kunci:}

Core design reactor, helium, HTGR, power density, thorium.

\section{Pendahuluan}

Pembangkit Listrik Tenaga Nuklir (PLTN) merupakan pembakit tenaga listrik yang relatif murah, aman, dan tidak mencemari lingkungan. Salah satu bahan bakar reaktor PLTN yang sering digunakan adalah uranium alam. Selain uranium alam, unsur lain yang dapat digunakan sebagai bahan bakar reaktor nuklir adalah thorium alam. Thorium alam merupakan bahan bakar fertil dengan menggunakan isotop Th232. Thorium terkandung dalam mineral monasit yang dapat ditemukan dalam batuan granit dari hasil sisa erosi. Sedangkan di Indonesia banyak bukit-bukit yang tersusun atas batuan sisa erosi. Oleh karena itu, pembangunan PLTN di Indonesia bisa dilakukan mengingat ketersediaan Thorium di Indonesia cukup melimpah (Ngadenin et al., 2014).

Salah satu jenis reaktor nuklir dalam PLTN yang digunakan yaitu High Temperatur Gas-cooled Reactor (HTGR). HTGR adalah salah satu jenis reaktor generasi IV yang banyak dikembangkan sebagai sumber energi listrik. Sesuai dengan namanya reaktor HTGR merupakan reaktor suhu tinggi yang menggunakan gas sebagai pendingin dan grafit sebagai moderator. HTGR memiliki skala Small Medium Reactor (SWR) atau reaktor skala kecil menengah, dengan

* Corresponding author.

E-mail addres: mutiautari1250@gmail.com 
fitur keselamatan melekat dan sistem keselamatan teknis pasif, sehingga mempunyai tingkat keselamatan dan keandalan yang baik (Ortensi, 2012). HTGR menggunakan pendingin berupa gas yang dikombinasikan dengan bahan teras yang tahan panas, gas yang sering digunakan adalah gas Helium (He) (Dewita et al., 2012).

Geometri 2 dimensi pada reaktor nuklir ada beberapa jenis seperti silinder, heksagonal, dan triangular. Perhitungan pada teras reaktor dilakukan secara 2 dimensi geometri heksagonal maka dilakukan desain HTGR model geometri heksagonal dua dimensi $(\mathrm{x}, \mathrm{y})$ dengan bahan bakar thorium hasil daur ulang menggunakan program SRAC. SRAC adalah program yang digunakan sebagai system kode neutronik untuk mensimulasikan perilaku nuklir di dalam teras reaktor sehingga penelitian ini bertujuan untuk menghasilkan desain reaktor yang memenuhi kriteria keselamatan melalui analisis neutronik. Analisis dilakukan dengan menggunakan CITATION pada program Standard thermal Reactor Analysis Code (SRAC) yang dikembangkan oleh Japan Atomic Energy Research Institute (JAERI) di Japan Atomic Energy Agency (JAEA) Jepang (Okumura, 2006).

\section{Metode Penelitian}

Alat dan bahan yang digunakan pada penelitian ini adalah seperangkat personal komputer dengan Operating System (OS) Linux Mint 18.2 Acer 32 bit dan program Standard Thermal Reactor Analysis Code (SRAC).

penelitian ini hal yang pertama dilakukan yaitu menentukan fraksi volume. Menentukan fraksi volume bertujuan untuk mengetahui perbandingan antara volume bahan bakar terhadap volume sel bahan bakar yang terdiri atas bahan bakar, cladding dan pendingin (Duderstadt \& Hamilton, 1976).

Setelah menghitung menentukan fraksi volume, kemudian dapat menentukan pengayaan. Penentuan pengayaan pada reaktor HTGR dilakukan agar reaktor berada dalam keadaan kritis $(k e f f=1)$. Persentase pengayaan yang digunakan pada penelitian ini dilakukan dengan dua bagian yaitu $4 \%-8 \%$ dan $8 \%$.

Setalah itu dapat menghitung densitas atom. Pada setiap reaktor terdapat komponen yaitu bahan bakar, cladding dan moderator yang akan dihitung densitas atomnya untuk digunakan sebagai input CITATION pada program SRAC.

Selanjutnya menentukan ukuran dan konfigurasi teras reaktor. penentuan ukuran teras reaktor kemudian mengubah-ubah konfigurasi bahan bakar tanpa mengubah ukuran dari teras reaktor (Okumura, 2007). Pada penelitian ini untuk menentukan ukuran dan konfigurasi teras reaktor digunakan model mesh triangular. Gambar 1 dalah contoh model dari inti reaktor HTGR dan contoh model mesh triangular.

Kemudian dapat melakukan perhitungan burn-up bahan bakar. Perhitungan burn-up dilakukan untuk perhitungan penyusutan dan produksi isotop sebagai fungsi waktu (Walter dan Reynolds, 1981). Pada penelitian ini periode burn up yang digunakan sebesar $20 \mathrm{GWd} / \mathrm{t}$ untuk pengayaan bagian pertama dan $30 \mathrm{GWd} / \mathrm{t}$ untuk pengayaan bagian kedua.

Selanjutnya dapat dilakukan penghitungan dengan CITATION. Hasil dari penghitungan densitas atom akan menjadi input pada penghitungan menggunakan CITATION pada SRAC (Björk et al., 2011).

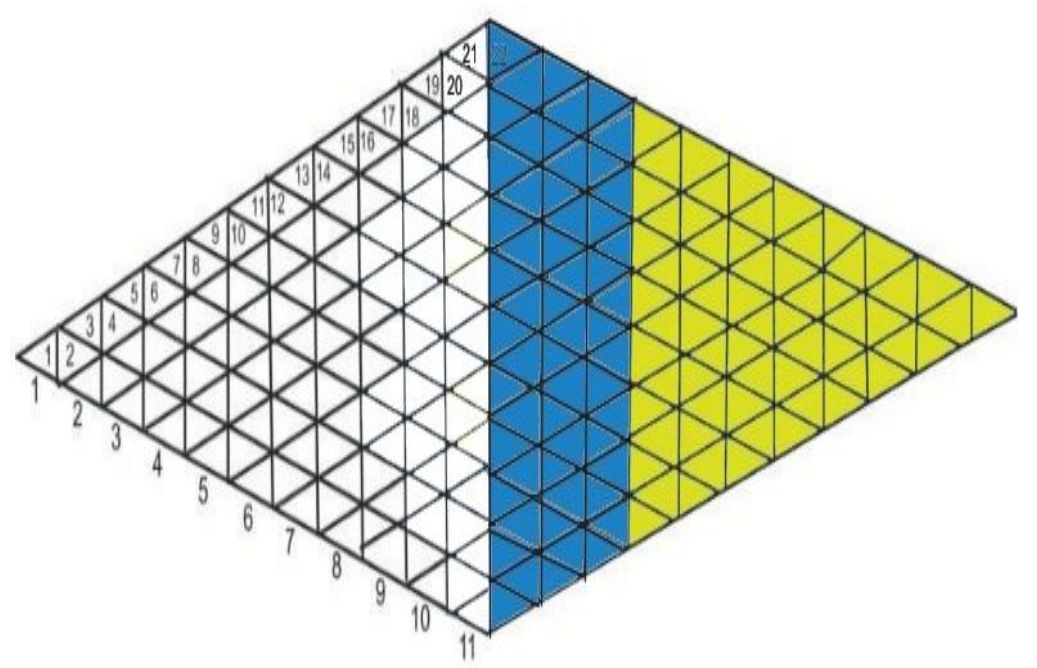

Pengayaan 4\%-8\% (inner fuel $20 \mathrm{GWd} / \mathrm{t})$

Pengayaan $8 \%$ (outer fuel 30 GWd/t)

Alackness

Gambar 1. Konfigurasi $1 / 6$ teras reaktor dengan jumlah mesh $22 \times 11$ 
Utari M, Yulianti Y, dan Riyanto A, 2020, Desain High Temperature Gas-Cooled Reactor (Htgr) Model Geometri Heksagonal Dua Dimensi Dengan Bahan Bakar Thorium Hasil Daur Ulang, Journal of Energy Material and Instrumentation Technology, Vol 1. No. 1, 2020

\section{Hasil Dan Pembahasan}

\subsection{Perubahan Pengayaan}

Pada peneitian yang telah diperoleh pengaruh pada persentase pengayaan bagian pertama yaitu $4 \%-8 \%$ dengan rentang $0,5 \%$. Sedangkan pada persentase pengayaan bagian kedua yaitu tetap sebesar $8 \%$. Hasil pengaruh pengayaan terhadap keff ditunjukkan pada Tabel 1.

Tabel 1. Pengaruh pengayaan terhadap $k_{\text {eff }}$

\begin{tabular}{ccccc}
\hline Bagian 1 (\%) & Bagian 2 $(\%)$ & Bagian $(x)(\mathrm{cm})$ & Bagian $(y)(\mathrm{cm})$ & $k_{\text {eff }}$ \\
\hline 4,0 & 8,0 & 200 & 200 & 0,8322546 \\
4,5 & 8,0 & 200 & 200 & 0,8605862 \\
5,0 & 8,0 & 200 & 200 & 0,8870626 \\
5,5 & 8,0 & 200 & 200 & 0,9116732 \\
6,0 & 8,0 & 200 & 200 & 0,9345804 \\
6,5 & 8,0 & 200 & 200 & 0,9559281 \\
7,0 & 8,0 & 200 & 200 & 0,9758794 \\
7,5 & 8,0 & 200 & 200 & 0,9945993 \\
8,0 & 8,0 & 200 & 200 & 1,0122317 \\
\hline
\end{tabular}

Berdasarkan Tabel 1, menunjukan nilai k_\{eff yang sudah melewati satu dan paling mendekati satu terletak pada pengayaan sebesar 8\% dengan nilai k_\{eff\} yang didapatkan sebesar 1,0122317. Pengayaan 8\% menghasilkan reaksi fisi yang telah terjadi di dalam reaktor. Semakin tinggi pengayaan bahan bakar yang digunakan maka reaksi fisi semakin besar sehingga meningkatnya jumlah neutron yang dihasilkan yang ditunjukkan pada Gambar 2.

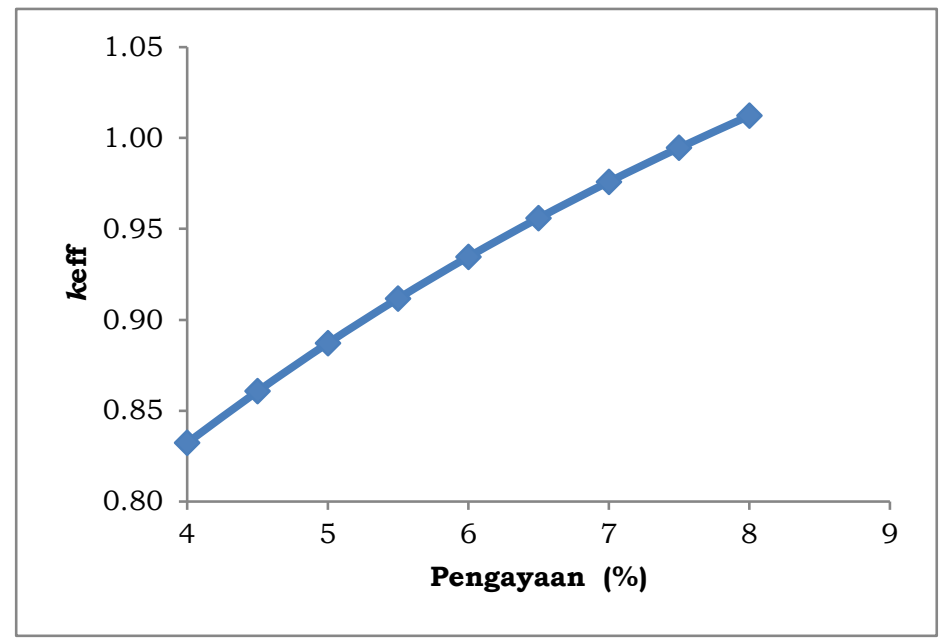

Gambar 2. Grafik pengaruh pengayaan terhadap $k_{\text {eff }}$.

\subsection{Ukuran Teras Reaktor}

Nilai hasil pengaruh pengayaan bahan bakar dengan nilai $\mathrm{k}_{\text {_\{ }} \mathrm{eff}$ \} yang paling mendekati satu akan digunakan untuk input pada CITATION, dengan mendapatkan ukuran teras reaktor yang diinginkan. Nilai keff yang sangat mendekati kekritisan dilakukan perubahan ukuran pada teras reaktor seperti yang dilakukan oleh penelitian sebelumnya oleh Saputra (2019) dan Dilaga (2019). Pada penelitian ini (x) yang sebelumnya $2200 \mathrm{~cm}$ akan diubah ukurannya menjadi 2002,05 - 2068,05 cm dengan perbedaan $11 \mathrm{~cm}$, sedangkan ukuran (y) yang sebelumnya 2200 $\mathrm{cm}$ diubah menjadi ukuran 2002,05 - 2068,05 cm dan nilainya tetap. Berdasarkan hasil yang diperoleh pada Tabel 2, ditunjukkan bahwa nilai keff yang mendekati satu terdapat pada $(\mathrm{x})=2035,05 \mathrm{~cm}$ dengan nilai keff sebesar 1,0000002. Pengaruh (x) terhadap nilai keff juga dapat dilihat pada Gambar $\mathbf{3}$ dan perubahan yang dilakukan pada (y) seperti perubahan yang dilakukan pada (x) dan dapat dilihat pada Tabel 3 dan Gambar 4. Hal ini menunjukan bahwa reaksi fisi yang dihasilkan pada teras reaktor semakin meningkat. 
Tabel 2. Pengaruh ukuran $(x)$ terhadap $k_{\text {eff }}$

\begin{tabular}{rlc}
\hline$x(\mathrm{~cm})$ & $y(\mathrm{~cm})$ & $k_{\text {eff }}$ \\
\hline 182,0045 & 185,0045 & 0,9986216 \\
183,0045 & 185,0045 & 0,9990858 \\
184,0045 & 185,0045 & 0,9995453 \\
185,0045 & 185,0045 & 1,0000002 \\
186,0045 & 185,0045 & 1,0004507 \\
187,0045 & 185,0045 & 1,0008968 \\
188,0045 & 185,0045 & 1,0013385 \\
\hline
\end{tabular}

Tabe1 3. Pengaruh ukuran baris $(y)$ terhadap $k_{\text {eff }}$

\begin{tabular}{ccc}
\hline$x(\mathrm{~cm})$ & $y(\mathrm{~cm})$ & $k_{\text {eff }}$ \\
\hline 185,0045 & 182,0045 & 0,9986216 \\
185,0045 & 183,0045 & 0,9990858 \\
185,0045 & 184,0045 & 0,9995453 \\
185,0045 & 185,0045 & 1,0000002 \\
185,0045 & 186,0045 & 1,0004507 \\
185,0045 & 187,0045 & 1,0008968 \\
185,0045 & 188,0045 & 1,0013385 \\
\hline
\end{tabular}

\subsection{Rapat Daya}

Berdasarkan hasil perhitungan pada CITATION didapatkan nilai dari rapat daya maksimum sebesar 550,3685 Watt $/ \mathrm{cm} 3$ yang terdapat pada titik $(\mathrm{x})=22$ dan titik $(\mathrm{y})=11$. Rapat daya relatif yang dihasilkan pada $(\mathrm{x})$ dapat dilihat pada Gambar 5 rapat daya maksimum yang didapatkan terletak pada titik $(\mathrm{x})=22$ dengan nilai faktor puncaknya 2,598174 dan dengan nilai rapat daya rata-rata yang dihasilkan yaitu $211,8290 \mathrm{Watt} / \mathrm{cm} 3$. Kemudian pada (y) dapat dilihat pada Gambar 6 rapat daya maksimum yang didapatkan terletak pada titik $(\mathrm{y})=11$ dengan nilai faktor puncaknya 2,333925 dan dengan nilai rapat daya rata-rata yang dihasilkan yaitu 235,8124 Watt/cm3. Maka nilai rapat daya relatif semakin meningkat pada $(\mathrm{x})$ dan $(\mathrm{y})$ yang mengarah ke dalam bagian bahan bakar. Hal ini disebabkan karena pada bagian bahan bakar merupakan tempat terjadinya reaksi fisi.

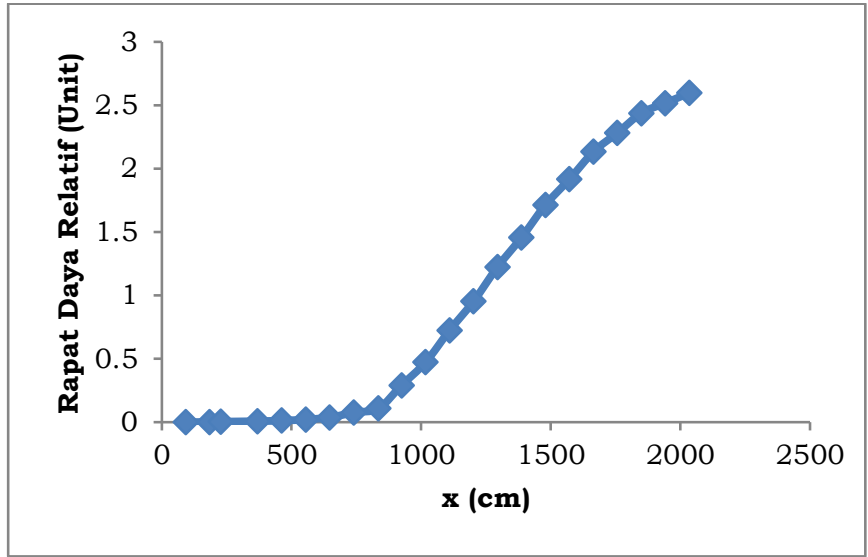


Utari M, Yulianti Y, dan Riyanto A, 2020, Desain High Temperature Gas-Cooled Reactor (Htgr) Model Geometri Heksagonal Dua Dimensi Dengan Bahan Bakar Thorium Hasil Daur Ulang, Journal of Energy Material and Instrumentation Technology, Vol 1. No. 1, 2020

Gambar 5. Grafik rapat daya realtif pada $(x)$ dengan panjang titik $(y) 2035,0495 \mathrm{~cm}$

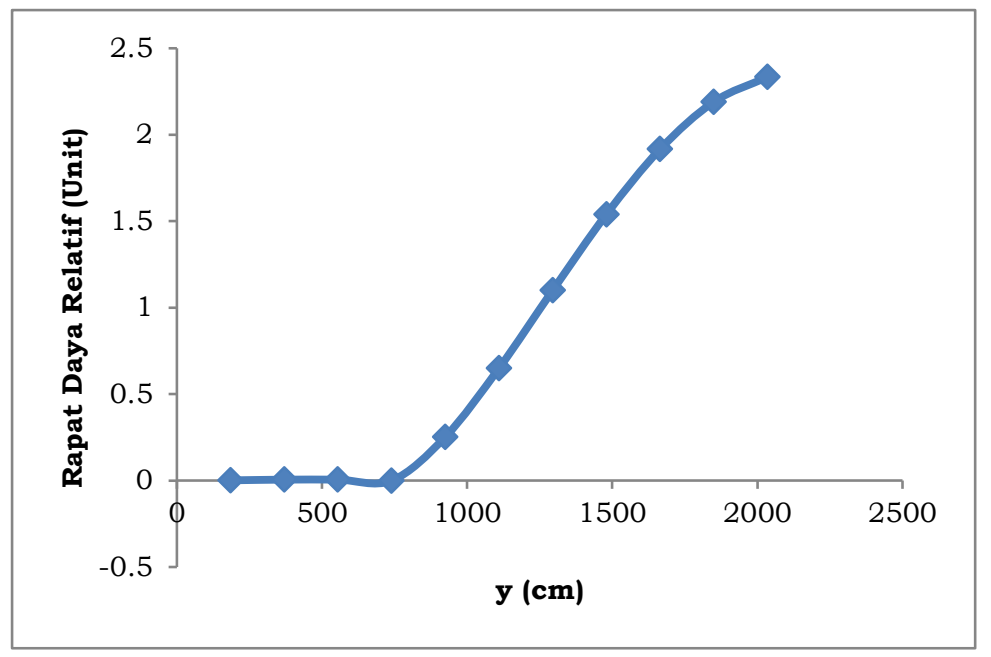

Gambar 6. Grafik rapat daya realtif pada $(y)$ dengan panjang titik $(x) 2035,0495 \mathrm{~cm}$

\subsection{Desain Teras Reaktor}

Data hasil yang diperoleh didapatkan desain teras rekator HTGR yang memenuhi standar kekritisan sebuah reaktor dan memiliki distribusi rapat daya yang cukup baik dengan energi yang optimal ketika pengayaan bahan bakar sebesar 8\%. Desain teras reaktor HTGR dapat dilihat pada Gambar 7 sehingga didapatkan model geometri teras reaktor yang ideal, dalam penentuan ukuran teras reaktor kemudian mengubah konfigurasi bahan bakar tetapi tidak mengubah ukuran teras reaktor (Okumura, 2007).

\section{Kesimpulan}

Kesimpulan yang diperoleh bahwa semakin besar persentase pengayaan bahan bakar, maka nilai keff yang dihasilkan semakin besar karena reaksi fisi yang terjadi pada teras reaktor lebih banyak. Desain teras reaktor HTGR yang memenuhi standar kekritisan berada pada ukuran (x) 2035,05 cm dan (y) 2035,05 cm dengan menggunakan pengayaan sebesar $8 \%$ yang menghasilkan nilai keff sebesar 1,0000002. Nilai rapat daya relatif semakin meningkat pada (x) dan (y) yang mengarah ke dalam bagian bahan bakar. Hal ini disebabkan karena pada bagian bahan bakar merupakan tempat terjadinya reaksi fisi.

\section{Daftar Pustaka}

Björk, K. I., Valentin, F., dan Christophe, D. 2011. Comparison of Thorium-Based Fuels with Different Fissile Components in Existing Boiling Water Reactors. Progress in Nuclear Energy. 53(6):618-625.

Dewita, E. 2012. Analisis Potensi Thorium Sebagai Bahan Bakar. Pengembangan Energi Nuklir. 14(1):45-56.

Dilaga, N. M., Yulianti, Y., dan Riyanto, A. (2019). Desain Teras Reaktor High Temperatur Gas-Cooled Reactor (HTGR) Model Mesh Triangular Dua Dimensi Berbahan Bakar Thorium Berpendingin Gas CO2. Teori Dan Aplikasi Fisika, 7(1):107-116.

Duderstadt, J.J., dan Hamilton, J. H. 1976. Nuclear Reactor Analysis. John Wiley and Sons Inc. USA.

Ngadenin., Syaeful, H., Widana, K. S., Sukadana, I. G., dan Indrastomo, F. D. 2014. Studi Potensi Thorium Pada Batuan Granit di Pulau Bangka. Jurnal Pengembangan Energi Nuklir. 16(2):143-155.

Okumura, K., Kugo, T., Kaneko, K., dan Thuchihashi, K. 2006. A Comprehensive Neutronics Calculation Code System. Japan. JAEA. 4-26.

Okumura, K. 2007. Introduction of SRAC for Reactor Phisics Analysis. Japan: JAEA. 10-15.

Ortensi, J. 2012. Prismatic Modular High Temperature Gas Cooled Reactor. IAEA Course on High Temperature Gas Cooled Reactor Technology Tsinghua University. Beijing.

Saputra, D. R., Yulianti, Y., dan Riyanto, A. 2019. Studi Desain High Temperature Gas-Cooled Reactor (HTGR) Berpendingin Gas Hidrogen Menggunakan Bahan Bakar Thorium. 7(1):99-106.

Walter, A. E., dan Reynolds, A. B. 1981. Fast Breeder Reactors. Pergamon Press. U.S.A. 